\title{
Nutritional Approach to Metabolic Changes Arising Out of Schizophrenia Therapy: Case Report
}

\author{
Aliye Ozenoglu ${ }^{1}$, Serdal Ugurlu ${ }^{2}$, Huriye Balci ${ }^{3}$ and Engin Eker ${ }^{4}$
}

\begin{abstract}
The case of a 35-year-old female patient who was diagnosed as schizophrenia treated with psychotrophic drugs nearly for 15 years is presented here. After the disease was diagnosed, the patient quit her university education and began to live inactively far from her social environment, usually spending lazy time at home. During this period, due to either the effects of drugs which have to be used on hormones affecting appetite and body weight or her decreased physical activity, her body weight increased by nearly $30 \mathrm{~kg}$. Anthropometric measurements, biochemical parameters and food diaries were evaluated at the beginning of the nutritional counseling and then repeated periodically. Upon obtaining biochemical findings, collaboration with other units started. The patient was educated on nourishing healthy and controlling body weight, also to bring about lasting behavioral changes. At the beginning of the therapy, among the biochemical measurements, insulin resistance was defined and metformin treatment was begun. Metformin therapy contributed to the patient's adaptation to the diet and improved glucose tolerance. In this way, it was possible to cope with the insulin resistance caused by anti-psychotic pharmacotherapy (clozapine) and the obesity which had developed as a result of clozapine. During the 18-month therapy the patient lost $27 \mathrm{~kg}$, her body fat was reduced by $10 \%(18 \mathrm{~kg})$ and BMI returned to normal levels. It is known that, many medications used in psychiatric disorders affect appetite and body weight. As seen in our patient metformin therapy causes weight loss and decreases insulin resistance. Both the illness and the medications used for treatment could affect the hormones which play a part in controlling body weight and the cytokines, as a result could change food preference and eating behavior which ultimately pave the way to obesity.
\end{abstract}

Key words: insulin resistance, anti-psycotic pharmacotherapy, schizophrenia, obesity

(DOI: 10.2169/internalmedicine.46.6323)

\section{Background}

Patients taking psychiatric therapy are prone to gain weight often accompanied by an increase in appetite or food hunger. It is hard to foresee its occurrence and timing, and thus this side effect frequently results in obesity and that causes some patients to discontinue therapy, even though it is effective.

Weight gain is the most striking side effect for patients treated with some second generation antipsychotic drugs and some mood stabilizers. Conventional antipsychotic drugs typically cause a slight moderate weight gain. Serious weight gain is often seen during tricyclic antidepressant therapy. Selective Serotonin Reuptake Inhibitors (SSRI) could cause weight gain during the first few weeks of therapy. However, some of those inhibitors stimulate gaining weight during long-term therapy. On the other hand, many antidepressant and antipsychotic drugs are reported not to cause weight gain and are even reported to reduce weight. There are several types of antipsychotic drugs including classical and atypic antipsychotics. Clozapine is an atypical antipsychotic that was introduced in 1990.

In this study, we aimed to investigate the changes in appetite, body weight and composition as well as hormonalmetabolic changes caused by psychotropic drug therapy and

\footnotetext{
${ }^{1}$ Department of Psychiatry, Cerrahpasa Medical Faculty, University of Istanbul, Istanbul, Turkey, ${ }^{2}$ Department of Internal Medicine, Cerrahpata Medical Faculty, University of Istanbul, Istanbul, Turkey, ${ }^{3}$ Central Laboratory, Cerrahpata Medical Faculty, University of Istanbul, Istanbul, Turkey and ${ }^{4}$ Department of Psychiatry, Cerrahpata Medical Faculty, University of Istanbul, Istanbul, Turkey

Received for publication October 20, 2006; Accepted for publication February 13, 2007

Correspondence to Mr. Aliye Özenoğlu, aliyeozenoglu@yahoo.com
} 
Table 1. Anthropometric Measurements and: Biochemical Parameters Measured at the Beginning (I) and End (II) of Therapy

\begin{tabular}{|l|l|l|}
\hline & I & II \\
Height $(\mathrm{cm})$ & 158 & \\
Weight $(\mathrm{kg})$ & 89 & 62 \\
BMI $(\mathrm{kg} / \mathrm{m} 2)$ & 35.7 & 24.8 \\
Waist circumference (cm) & 102 & 83 \\
Hip circumference (cm) & 122 & 98 \\
Wais/Hip ratio & 0,83 & 0,84 \\
Body fat (\%) & 43,2 & 33,0 \\
FBG mg/dl & 104 & 98 \\
Insulin MIU/ml & $29.9^{*}$ & 10.2 \\
\% HbAIC & $6.1 *$ & 5.4 \\
HOMa $-\mathrm{R}$ & $7.42^{*}$ & 2.46 \\
TG mg/dl & 75 & 78 \\
T.kol. mg/dl & 191 & 177 \\
HDL mg/dl & 62 & 65 \\
LDL mg/dl & 115 & 96 \\
Hgb g/dl & 12.4 & 12.8 \\
\% Hct & 37.5 & 39.0 \\
B12 Vit pg/ml & 556 & 307 \\
Folat ng/ml & 18.9 & 11.9 \\
TSH miu/ml & 1.27 & 1.67 \\
ALT U/L & 16 & 15 \\
AST U/L & 23 & 21 \\
Uric acid & $6.0^{*}$ & 4.5 \\
Zinc mg/dl & 81 & 78 \\
\hline
\end{tabular}

to research the efficiency of nutritional support in curing potential physical, hormonal and metabolic disorders.

\section{Method}

A 35-year-old female patient who had been constantly treated for schizophrenia with psychotropic drugs for about 15 years was enrolled in the study. Following the diagnosis, she discontinued her university education and started to live mostly at home, away from social circles and with a minimum of physical activity. During this period, the patient gained about $30 \mathrm{~kg}$ in body weight due to the effect of drugs on hormones affecting appetite and body weight as well as the minimum level of physical activity. She had been taking clozapine (100 mg/day) as an antipsychotic for about 15 years. Bioelectrical impedance analysis (Bodystat Quadscan 4,000, England) was performed and biochemical parameters were measured using an Olimpus AU800 Autoanalyze (Olympus, Tokyo, Japan). The food consumption records were computed by means of the BeBiS (version 4) computer software (1). We treated her with metformin (850 $\mathrm{mg} \times 2 /$ day). During the 18 -month follow-up, the patient was instructed about healthy nutrition and advised about the control of body weight in an effort to ensure permanent behavioral change. We tried to decrease the saturated fat and overall lipid content of her diet and also to increase the fibres in diet. At the beginning of the diet therapy we applied intermediate grade calorie restriction; $1,600 \mathrm{kcal} / \mathrm{day}$ was planned for the patient. Our aim was to lose $5-10 \%$ of the existing body weight. This aim was achieved with the patient at about 4 months. Weight losing persisted with the Intermedia degree physical activity increasing (walking 30 min/day, 5 days in a week ). Nutritional therapy and training sessions were generally conducted alone with the patient and sometimes with the patient's mother.

\section{Results}

Table 1 lists the anthropometric measurements and the biochemical parameters of our patient at the beginning and end of the diet therapy. The monthly weight follow-up is shown in Fig. 1. Blood pressure was $120 / 80$ at the beginning. It persisted as systolic from 120-110 and diastolic from 70-80 in the follow-up.

As insulin resistance was detected in the biochemical measurements taken at the beginning of therapy (HOMA-R= 7.42), the patient was referred to the Endocrine Polyclinic for Metformin therapy which facilitated the patient's adaptation to the diet and the improvement of her glucose tolerance. We were thus capable of overcoming the insulin resis- 


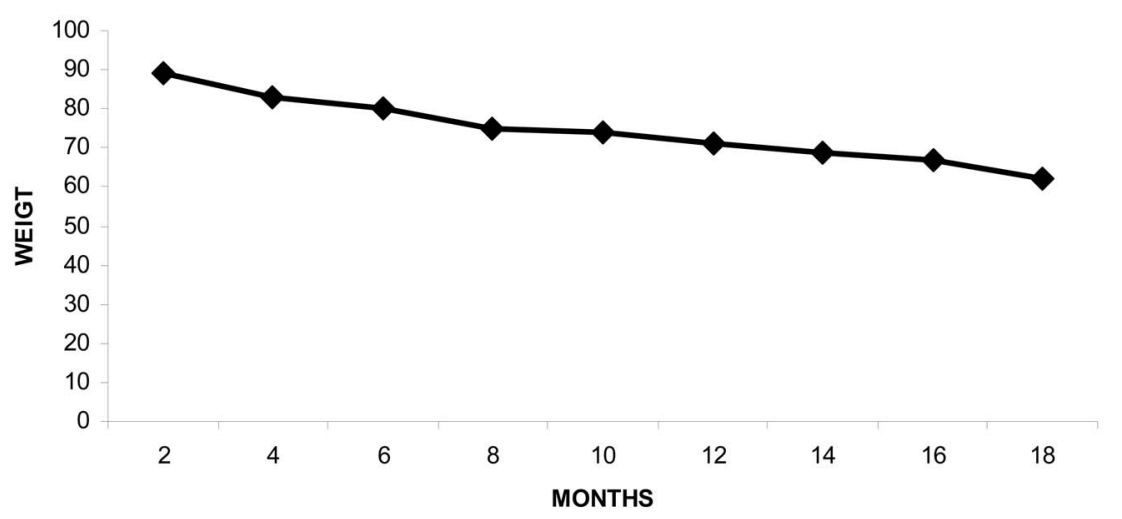

Figure 1. Wight follow ups per every 2 months.

Table 2. Average Daily Food Consumption Values before (I) and after (II) the Diet Therapy

\begin{tabular}{|l|l|l|}
\hline Nutrients & I & II \\
Energy (kcal) & 2047 & 1114 \\
Protein (g) \% & $(91.2) \% 18$ & $(56.9) \% 21$ \\
Fat (g) \% & $(81.3) \% 35$ & $(26.8) \% 22$ \\
Carbohydrate (g) \% & $(233) \% 46$ & $(155) \% 57$ \\
Fiber (g) & 22.1 & 26.3 \\
Cholesterol (mg) & 214 & 120 \\
Sodium (mg) & 3243 & 2066 \\
Potassium (mg) & 2541 & 3382 \\
Magnesium (mg) & 414.7 & 1032.3 \\
Calcium (mg) & 239.7 & 301.4 \\
Phosphorus (mg) & 1080.4 & 1059.6 \\
Iron (mg) & 13.2 & 12.0 \\
Zinc (mg) & 11.5 & 9.8 \\
\hline
\end{tabular}

tance caused by antipsychotic pharmacotherapy and the subsequent obesity. During the 18-month treatment, she lost 27 $\mathrm{kg}, 10 \%$ of her initial body fat $(18 \mathrm{~kg})$ and achieved a BMI closer to the normal range.

Table 2 shows a comparison of our patient's average food consumption before and after the diet therapy. Initially, our patient's intake of energy, protein, fat, sodium and phosphorus was significantly high and thus her intake of calcium, magnesium and iron was low. Efforts were used during the diet therapy to ensure the conformity of nutrient consumption to recommended levels and nutritional supplements were used when necessary.

\section{Discussion}

Not all weight changes observed in psychiatric patients are due to the drug therapy. Disorder-related actions contributing to gain weigh. include hunger in atypical depression and the restoration of body weight following symptomatic weight loss due to loss of appetite. The comparison of the premorbid, pre-therapy and current body weight help to distinguish disorder-related weight gain from drug-related weight gain. Although changes in body weight partially reflect the recovery from weight loss or gain related to psychiatric disorders, this statement does not seem to be relevant for weight gain exceeding the premorbid body weight (2).

The present patient, who was treated with various antipsychotic drugs for about 15 years, gained nearly $30 \mathrm{~kg}$ during this period. Due to her resistance to therapy, she had been on a classic antipsychotic (clozapine) and a selective serotonin reuptake inhibitor (SSRI) (Fluoxetine) therapy as a last resort. She had a normal body weight $(60 \mathrm{~kg})(\mathrm{BMI}=24.0$ $\mathrm{kg} / \mathrm{m}^{2}$ ) before the disorder and became obese (BMI= 35.7 $\mathrm{kg} / \mathrm{m}^{2}$ ) as a result of the appetite and hormonal changes caused by the disorder and the drugs. Initial biochemical tests revealed hyperinsulinemia, insulin resistance (HOMA$\mathrm{R}=7.42$ ) and hyperurisemia, and revealed that the measured body fat percentage was way above the expected level (Table 1 and Table 2). Although our patient was considered to be obese on the basis of her BMI, she was actually morbid obese according to her body fat percentage (3) and in conformity with the metabolic syndrome diagnosis criteria (4).

The visceral fat mass is positively correlated with the amount of insulin resistance (5). Our patient's BMI, circumference of waist of circumference and body fat ratio (Table 1) are compatible with hyperinsulinemia. In diagnosing abdominal obesity, waist and waist/hip ratio measurements are simple and sensitive measurements. In women, a waist exceeding $88 \mathrm{~cm}$ and the waist/hip ratio exceeding 0.85 is considered to indicate an increased risk in terms of obesityrelated diseases and mortality (6-8).

Weight gain caused by a psychotropic drug often precedes a sudden increase in appetite and the preference for sweet and greasy food (9). This condition was established by Paykel who first made use of the term "carbohydrate craving" (10). If a person is suffering from excessive food craving, the associated increase in food consumption is a potential reason for weight gain. Many authors reported that gaining weight is correlated with the enhancement of clinical symptoms $(11,12)$. In a study conducted by Czobor et al (13), the positive relation which was found between weight gain and the antipsychotic effect of clozapine and olanzap- 
ine could not be associated with the risperidone and haloperidol therapy.

It was suggested that psychotropic drugs which cause weight gain, activate the TNF- $\alpha$ system (14) and thus the TNF- $\alpha$ system is an early and sensitive indicator of weight gain (15). It was assumed that the decrease in the TNF- $\alpha$ receptor sensitivity could impair the body weight control mechanism and thus cause an increase in calorie intake. It was proven that psychotropic drugs typically causing an increase in body weight such as clozapine, olanzapine activate the TNF- $\alpha$ system and leptin by increasing the plasma levels of the said cytokines and soluble cytokine receptors (15). For this reason, it is believed that the stimulation of those multifunctional mediators could play a role in body weight changes related to drugs.

In a study conducted on 31 patients treated with clozapine (16), it was reported that gaining weight is significant during the initial 12 weeks of therapy. It was concluded that the initial deviation from normal body weight is an important determinant of subsequent weight gain.

In a prospective, longitudinal study covering constant clozapine therapy which lasted for more than 5 years, the patients' body weight which increased constantly up to an average of $11.6 \mathrm{~kg}$ for the first 4 years was thereafter stabilized (17).

It is also suggested that weight gain caused by psychotropic drug therapy could be associated with an increase in the leptin levels. During acute treatment of schizophrenia with clozapine, the serum leptin increased by two fold two weeks after the start of therapy and remained at a high level during the first 10 weeks. Meanwhile, body weight was increased by an average of $4.2 \mathrm{~kg}$ (18). In patients treated with clozapine or olanzapine for 4 weeks, weight gain of 2.3 and $3.9 \mathrm{~kg}$, respectively, was observed and in conformity with increased leptin secretion. It was also detected that patients treated with haloperidol or not using psychotropic drugs did not gain weight and had constant leptin levels (19).

Among second generation antipsychotic drugs, clozapine and olanzapine are considered to have a high risk for impaired glucose metabolism. This condition was first recognized with the reporting of many cases in which diabetic ketoacidosis developed as a result of clozapine therapy, was cured with the discontinuation of clozapine therapy and then relapsed with the recommencement of therapy. In a study (20), the risks of diabetes and hyperlipidemia in young patients treated with clozapine were found to be 2.5 times and 2.4 times higher, respectively, than in patients receiving conventional antipsychotic drugs. In a study conducted on psychiatric patients hospitalized and treated with storage formulas of clozapine or conventional antipsychotic drugs, it was found that 6 out of 63 patients receiving haloperidol, zuclopentixol, fluphenazine, perphenazine or flupentixol and 13 out of 60 patients receiving clozapine suffered from type 2 diabetes or impaired glucose tolerance (21).

In a study investigating the long-term effects of antipsy- chotic drugs on body weight and the glucose mechanism, 82 patients on constant clozapine therapy were monitored for 5 years (22). A weight gain of up to $11.6 \mathrm{~kg}$ was observed by the end of the 4 th year of treatment while as many as $36 \%$ of patients were newly diagnosed with diabetes. While the serum cholesterol increased in a statistically insignificant manner, the increase in triglycerides was found to be statistically significant. As only two out of 82 patients had a positive family history for diabetes, it was reported that this high incidence of diabetes could not be explained by an increased genetic risk.

It is surprising that all drugs which were previously proven to induce a significant weight gain (clozapine, olanzapine, amitriptyline and mirtazapine) apparently activate the TNF- $\alpha$ system. The activation of the TNF- $\alpha$ system, which seems to be specific for psychotropic drugs, induces weight gain, as drugs not affecting or even reducing body weight such as haloperidol, venlafaxine and paroxetine are known not to affect the TNF- $\alpha$ system $(19,23-26)$.

Potentials for an increase in weight for any drugs would be initially recommended to increase the patient's adaptation to the psychotropic drug and to reduce the metabolic risks of weight gain. Diet, exercise and changes in lifestyle are considered to be the gold standards of the obesity therapy $(27,28)$. On the other hand, this approach could be found to be lacking in cases when it is necessary to administer drugs affecting appetite and body weight. In order to increase the success of therapy and to reduce risks of illness associated with obesity, therapy could be supplemented with pharmacotherapy. Today, the use of weight reduction drugs is only recommended along with diet, exercise and behavioral modification. The combined use of those two approaches could be complementary. While behavioral therapy assists obese individuals to control external stimuli about food, pharmacotherapy could control the internal environment by reducing hunger, the intensity of eating or the absorption of food.

There are no strategies established for the specific treatment of gaining weight caused by psychotropic drugs. Weight gain arising from the use of psychotropic drugs could be due to underlying psychiatric disorders. For this reason, the necessity of the use of topiramate, histamine $\mathrm{H} 2$ antagonists, opiate antagonists, dopaminergic or serotoninergic drugs should be considered.

Weigh gain resulting from antipsychotic therapy is a frequently encountered problem. It is believed that serotonergic, dopaminergic, adrenergic, cholinergic, histaminergic and glutaminergic receptors could act as mediator for weight gain associated with therapy (29). It is also suggested that the disregulation of the sex hormone and impairment of insulin sensitivity can also play a role.

Today, the HOMA-R (Homeostasis model assessment) value is used in the determination of the degree of insulin resistance (30). In cases when HOMA-R is more than 4.0, the patient is diagnosed as having insulin resistance. The addition of pharmacological agents (metformin, roziglitazone) 
to diet and exercise in treatment is considered to be a fairly efficient method in overcoming insulin resistance, obtaining weight loss and reducing metabolic risks (30-33). The present patient's HOMA-R value was calculated as 7.42 at the beginning of treatment. After being referred to the Endocrine Polyclinic, the patient has taken metformin $(850 \mathrm{mg} \times$ 2) therapy. According to measurements performed at the end of therapy, the HOMA-R value was reduced to 2.46 .

Metformin is an oral anti-diabetic drug increasing the endogenous sensivity of insulin (biguanide). It represses hepatic glucose production and reduces insulin resistance but does not stimulate insulin secretion (33). Although metformin therapy could cause slight body weight loss and improve lipid levels, it does not cause hypoglycemia.

According to the report of a study performed on adolescent subjects, it is suggested that metformin which is an anti-diabetic drug could be effective in reversing the weight gain caused by olanzapine, risperidone, quetiapine and valproate (34). The body weight of 19 patients receiving any one of those medications was reduced by an average of 2.93 $\mathrm{kg}$ at 12 weeks after the addition of $500 \mathrm{mg}$ t.i.d metformin.

Diet plays an important role in overcoming insulin resistance. Exercise, reduction of calorie intake and reduction of body weight are among the factors positively affecting insulin. Preferring food articles supplying the cells with glucose at a constant rate and generating the need for a moderate level of insulin could help prevent insulin resistance (32). The glycemic index is used to establish the rate with which any given food article supplies glucose to the blood and thus stimulates the insulin secretion. Food articles with a high content of soluble fibers such as leguminosae, wholeseed grains, fresh fruits and vegetables have a low glycemic index and thus carbohydrate forms are the preferred carbohydrate forms. In the adjustment of blood glucose levels, it is also important to plan varieties of food taken during meals. Consuming food containing proteins, fat and carbohydrate during main and interim meals ensures a better blood glucose level and less insulin secretion than consuming food containing only carbohydrates (32).

Mechanism of food consumption before therapy revealed that the present patient's average daily calorie, protein, fat, carbohydrate, sodium and phosphorus intake was high while the calcium, magnesium and fiber consumption was low (Table 2). Nutritional recommendations were developed on the basis of the patient's clinical state and biochemical parameters, and efforts were used throughout the therapy to ensure permanent changes in the patient's nutritional habits. When the food consumption records are examined at the end of the treatment, it becomes apparent that the total daily calorie, macro nutrient and especially saturated fat and cholesterol and sodium intake were reduced significantly and that the fiber, calcium and magnesium intake were increased. It is believed that the new nutritional habits and change in the style of the patient's life greatly contributes to postponing or preventing the potential complications of insulin resistance, impaired glucose tolerance and metabolic syndrome arising from the use of psychotropic drugs.

\section{Conclusion}

It is known that many drugs used to treat psychiatric disorders affect appetite and body weight. Both the disorder itself and the drugs used to treat it could alter food preference and eating behavior by influencing the hormones playing a role in controlling body weight and cytokines and thus subsequently cause obesity. For this reason, while planning antipsychotic therapy for each and every patient, not only the drug's effect on psychiatric symptoms but also the increase in BMI and associated health risks should be taken into account.

Based on the findings of this study, it is concluded that early and comprehensive nutritive consultation provided to patients requiring psychiatric treatment can be beneficial in preventing or overcoming metabolic problems.

\section{References}

1. Özenoğlu A. BeBiS, Beslenme Bilgi Sistemi (4. versiyon), (Türkçe versiyon editörü). 2004 (in Turkish).

2. Baptista T, Teneud L, Contreras Q, et al. Lithium and body weight gain. Pharmacopsychiatry 28: 35-44, 1995.

3. Özenoğlu A, Can G, Hatemi H. Beden kitle indeksine göre normal ağırlıklı, fazla kilolu, obez ve morbid obez olarak gruplandırılan yetişkin kadın ve erkeklerde vücut kompozisyonu referans değerleri. Endokrinolojide Yönelişler 10: 58-63, 2001 (in Turkish).

4. Matthews DR, Hosker JP, Rudenski AS, Naylor BA, Treacker DF, Tumer RC. Homeostasis model assesment: insulin resistance and B-cell function from fasting plasma glucose and insulin concentrations in man. Diabetologia 28: 412-419, 1985.

5. Groop L, Orho-Melander M. The dysmetabolic syndrome. J Intern Med 250: 105-120, 2001.

6. Özenoğlu Aliye. Obezitede Medikal Nutrisyon Tedavisi. I. Baskı, Dilek Ofset, İstanbul, 2001 (in Turkish).

7. PI-Sunyer FX: Obesity. in: Shils Hodern Nutrition in Health and Disease. 9th ed. ME, Olson JA, Shike M, Ross AC, Eds. Lippincott Williams and Wilkins, Philadelphia, 1999: 1395-1414.
8. Pouliot MC, Despres JP, Lemieux S, et al. Waist circumference and abdominal sagittal diameter: Best simple antropometric indexes of abdominal visceral adipose tissue accumulation and related cardiovascular risk in man and women. Am J Cardiol 73: 460-468, 1994.

9. Kazes M, Danion JM, Grange D, et al. Eating behaviour and depression before and after antidepressant treatment: a prospective, naturalistic study. J Affect Disord 30: 193-207, 1994.

10. Paykel ES, Mueller PS, Del V. Amitriptyline, weight gain and carbohydrate craving: a side effect. Br J Psychiatr 123: 501-507, 1973.

11. Klett CJ, Caffey EM. Weight changes during treatment with phenothiazine derivatives. J Neuropsychiatr 2: 102-108, 1960.

12. Singh MM, De Dios LV, Kline NS. Weight as a correlate to clinical response to psychotropic drugs. Psychosomatics 11: 562-570, 1970.

13. Czobor P, Volavka J, Sheitman B, et al. Antipsychotic-induced weight gain and therapeutic response: a differential association. J Clin Psychopharmacol 22: 244-251, 2002. 
14. Pollmacher T, Schuld A, Kraus T, Haack M, Hinze-Selch D. On the clinical relevance of clozapine-triggered release of cytokines and soluble cytokine-receptors. Fortschr Neurol Psychiatr 69: 6574, 2001 (in German).

15. Hinze-Selch D, Schuld A, Kraus T, et al. Effects of antidepressants on weight and on the plasma levels of leptin, TNF- and soluble TNF receptors: a longitudinal study in patients treated with amitriptyline or paroxetine. Neuropsychopharmacology 23: 13-19, 2000

16. Hummer M, Kemmler G, Kurz M, Kurzthaler I, Oberbauer H, Fleischhacker WW. Weight gain induced by clozapine. Eur Neuropsychopharmacol 5: 437-440, 1995.

17. Henderson DC, Cagliero E, Gray C, et al. Clozapine, diabetes mellitus, weight gain and lipid abnormalities: a five year naturalistic study. Am J Psychiatry 157: 975-981, 2000.

18. Bromel T, Blum WF, Ziegler A, et al. Serum leptin levels increase rapidly after initiation of clozapine therapy. Mol Psychiatry 3: 7680, 1998.

19. Kraus T, Haack M, Schuld A, et al. Body weight and leptin plasma levels during treatment with antipsychotic drugs. Am J Psychiatry 156: 312-314, 1999.

20. Lund BC, Perry PJ, Brooks JM, Arndt S. Clozapine use in patients with schizophrenia and the risk of diabetes, hyperlipidemia and hypertension. Arch Gen Psych 58: 1172-1176, 2001.

21. Hagg S, Joelsson L, Mjorndal T, Spigset O, Oja G, Dahlqvist R. Prevalance of diabetes and impaired glucose tolerance in patients treated with clozapine compared with patients treated with conventional depot neuroleptics. J Clin Psych 59: 294-299, 1998.

22. Henderson DC, Cagliero E, Gray C, et al. Clozapine, diabetes mellitus, weight gain and lipid abnormalities: a five year naturalistic study. Am J Psychiatr 157: 975-981, 2000.

23. Pollmacher T, Hinze-Selch D, Mullington J. Effects of clozapine on plasma cytokine and soluble cytokine receptor levels. J Clin Psychopharmacol 16: 403-409, 1996.

24. Kraus T, Haack M, Schuld A, Hinze-Selch D, Koethe D, Pollmacher T. Body weight, the tumor necrosis factor system and leptin production during treatment with mirtazapine or venlafaxine. Pharmacopsychiatry 35: 220-225, 2002.

25. Hinze-Selch D, Deuschle M, Weber B, Heuser I, Pollmacher T. Effect of coadministration of clozapine and fluvoxamine versus clozapine monotherapy on blood cell counts, plasma levels of cytokines and body weight. Psychopharmacology (Berl) 149: 163$169,2000$.

26. Pollmacher T, Hinze-Selch D, Fenzel T, Kraus T, Schuld A, Mullington J. Plasma levels of cytokines and soluble cytokine receptors during treatment with haloperidol. Am J Psychiatry 154: 1763-1765, 1997.

27. Hanif MW, Kumar S. Pharmacological management of obestiy. Expert Opin Pharmacother 3: 1711-1718, 2002.

28. Fernstrom MH, Fernstrom JD. The new role of fharmacotherapy for weight reduction in obesity. Int J Clin Pract 56: 683-686, 2002.

29. Werneke U, Taylor D, Sanders TA. Options for pharmacological management of obesity in patiens treated with atypical antipsychotics. Int Clin Psychopharmacol 17: 145-160, 2002.

30. Matthews DR, Hosker JP, Rudenski AS, Naylor BA, Treacker DF, Tumer RC. Homeostasis model assesment: insulin resistance and B-cell function from fasting plasma glucose and insulin concentrations in man. Diabetologia 28: 412-419, 1985.

31. Watson GS, Craft S. The role of insulin resistance in the pathogenesis of Alzheimer's disease: implications for treatment. CNS Drugs 17: 27-45, 2003.

32. Mathai K. Nutrution in the adult years. in: Krause's Food, Nutrition and Diet Therapy; 11th ed. Mahan LK, Escott-Stump S, Eds. Saunders, Philadelphia, Pennsylvania, USA, 2004: 313.

33. Franz MJ. Medical nutrition therapy for diabetes mellitus and hypoglycemia of nondiabetic origin. in: Krause's Food, Nutrition and Diet Therapy; 11th ed. Mahan LK, Escott-Stump S, Eds. Saunders, Philadelphia, Pennsylvania, USA, 2004: 798-810.

34. Morrison JA, Cottingham EM, Barton BA. Metformin for weight loss in pediatric patients taking psychotropic drugs. Am J Psychiatr 159: 655-657, 2002.

(C) 2007 The Japanese Society of Internal Medicine http://www.naika.or.jp/imindex.html 